\title{
O DILEMA DAS COMUNIDADES TRADICIONAIS EM UNIDADES DE CONSERVAÇÃO: O CASO DA COMUNIDADE MUMBUCA NO PARQUE ESTADUAL DO JALAPÃO (TO)
}

\author{
THE DILEMMA OF THE TRADITIONAL COMMUNITIES IN ECOLOGICAL \\ PARK: THE CASE OF THE COMMUNITY MUMBUCA \\ IN JALAPÃO STATE PARK (TO)
}
EL DILEMA DE COMUNIDADES TRADICIONALES EN ÁREAS PROTEGIDAS: EL CASO DE LA COMUNIDAD MUMBUCA EN EL PARQUE ECOLÓGICO JALAPÃO (TO)

Waldecy Rodrigues - Universidade Federal do Tocantins - Palmas - Tocantins - Brasil

waldecy@terra.com.br

Thelma Valentina Fredrych - Instituto Federal de Educação, Ciência e Tecnologia do Tocantins

- Paraíso do Tocantins - Tocantins - Brasil

thelmavaletina@uol.com.br

\section{Resumo}

No atual debate internacional sobre as áreas de preservação ambiental, duas correntes de pensamento destacam-se: os preservacionistas, que defendem que a área preservada não deve ser coabitada por seres humanos, mesmo sendo as comunidades tradicionais; e os conservacionistas, que reforçam a importância do conhecimento das populações tradicionais para 0 alcance de um possível equilíbrio entre a vida social humana e a manutenção dos sistemas naturais. A legislação ambiental brasileira procura conciliar tendências e interesses de preservacionistas e conservacionistas, porém existem ainda muitas resistências quanto à possibilidade de haver modelos de unidades de conservação que integrem as populações tradicionais às áreas protegidas. 0 estudo da comunidade Mumbuca do Parque do Jalapão (TO) teve como objetivo demonstrar uma clara situação de conflito existente em relação à sua permanência nos limites do Parque Estadual ou sua remoção, conforme institucionalizado pela lei que implantou a unidade de conservação. 0 s resultados desta pesquisa apontam que a comunidade Mumbuca não tem como sobreviver fora da área em que vive há mais de cem anos e, tampouco, reproduzir-se culturalmente dentro das especificações de Unidade de Proteção Integral e suas normas de manejo, uma vez que estas não consideram a presença das populações humanas dentro delas. Assim sendo, não é a comunidade Mumbuca que deve se retirar do seu local centenário, mas a autoridade estadual é que deve ter o mínimo de sensatez e encontrar uma saída institucional e dialogada para o uso sustentável do Parque Estadual do Jalapão.

Palavras-chave: comunidades tradicionais, Unidades de Conservação, Parque Estadual do Jalapão, comunidade Mumbuca, sustentabilidade, legislação ambiental.

\section{Abstract}

In the current international debate on the formation of environmental preservation areas two schools of thought are: preservationists who argue that the area should be preserved not occupied by humans, even traditional communities, while conservationists that reinforce the importance of knowledge traditional populations to achieve a balance between possible human social life and the maintenance of natural systems. Brazilian environmental legislation seeks to reconcile interests and trends among preservationists and conservationists, but there is still plenty of resistance the possibility of having models of conservation that integrates people 
traditional and protected areas. The study of the Mumbuca Community, from the Jalapão Park in Tocantins, had the aim to demonstrate a clear conflict situation between its permanence within the limits of the State Park or its removal as institutionalized by the law that implemented the conservation unity. The research results point out that the Mumbuca Community cannot live outside the area it has lived for more than a hundred years; it cannot live anywhere else, unless it is its place. Moreover, it cannot culturally reproduce itself within the Unity for Conservation of Integral Protection and its management norms, once they do not take into account the presence of the human populations under their borders. The Mumbuca Community must not retire itself from its centenary place, the local authorities must have a minimum of common sense and find an institutional solution for the sustainable use of the Jalapão State Park.

Keywords: traditional communities, protected areas, Jalapão State Park, Mumbuca community, sustainability, environmental legislation.

\section{Resumen}

En el actual debate internacional sobre las áreas de preservación ambiental tiene dos corrientes de pensamiento, conservacionistas que defienden que la zona no debe ser coabitada por los seres humanos, incluso las comunidades tradicionales, y los conservacionistas que refuerzan la importancia de los conocimientos tradicionales en el alcance de un equilibrio posible entre la vida social humana y el mantenimiento de los sistemas naturales. La legislación ambiental brasileña pretende conciliar las tendencias e intereses entre los conservacionistas y ecologistas, pero todavía hay mucha resistencia a la posibilidad de contar con modelos de conservación que integra traccionales poblaciones en áreas protegidas.

El estudio sobre la Mumbuca Comunidad pretende demostrar un claro conflicto entre su existencia o remoción dentro de los límites del Parque Jalapão. Los resultados de la encuesta indican que los residentes Mumbuca no tienen forma de vivir fuera del área que usted vive más de cien años, ni reproducirse culturalmente dentro de las especificaciones Unidad de Conservación de Protección Integral. No son los residentes de la Comunidad Mumbuca deben retirar su centenario local, pero la autoridad estatal que tendrá el menor sentido y encontrar una salida institucional y dialogada para el uso sostenible del Parque Jalapão.

Palabras clave: comunidades tradicionales, unidades de conservación, Parque Estatal Jalapão, comunitarios Mumbuca, sustentabilidad, legislación ambiental.

\section{Introdução}

Em um momento em que a preservação do meio ambiente apresenta-se como questão essencial nas discussões e práticas que visam à melhoria de qualidade de vida das populações humanas e a continuidade dos meios essenciais à sobrevivência biológica de todas as espécies, uma incerteza aflige a nossa racionalidade: será, de fato, possível a existência concreta de uma relação dialogicamente benéfica entre as sociedades humanas e a natureza?

Na busca por uma resposta, diversas correntes de pensamento começaram a surgir e a defender suas posições. Dentre elas, destacam-se a linha preservacionista e a linha conservacionista. Originalmente, os preservacionistas eram aqueles que aboliam a ideia de domínio do homem sobre a natureza. Eles consideravam o homem como parte da natureza, porém no mesmo status da fauna e flora. Essa corrente de pensamento foi 
aquela adotada no processo de criação dos parques norte-americanos, sob a justificativa de que esta seria a alternativa mais eficiente para a minimização dos impactos da civilização sobre o meio ambiente.

Já a linha de pensamento conservacionista reforça a importância do conhecimento das populações tradicionais para o alcance de um possível equilíbrio entre a vida social humana e a manutenção dos sistemas naturais. Uma constatação a priori contraditória forneceu as bases para o surgimento desta linha de pensamento: na observação de alguns parques (nos EUA) percebeu-se perda de biodiversidade, mesmo que estes estivessem isolados de populações humanas; e, ao mesmo tempo, observou-se que áreas de florestas, cerrados, matas, faixas litorâneas ocupadas por populações tradicionais continuavam extremamente conservadas.

Ora, daí decorre a ideia de que a presença e a reprodução da vida social humana nas áreas de preservação ambiental não implicam, necessariamente, degradação do meio ambiente. A constatação de que comunidades tradicionais lograram a preservação dos recursos naturais das áreas que ocuparam ao longo de sua história fornece indicativos extremamente relevantes para a confiança em um benefício recíproco decorrente da relação homem/natureza. É sob essa perspectiva que este artigo se estrutura.

No ano de 2000, foi aprovada a Lei $\mathrm{n}^{\circ}$ 9.985, que implantou o Sistema de Unidades de Conservação no Brasil. A legislação ambiental brasileira, para implantação das Unidades de Conservação, procura conciliar tendências e interesses defendidos por preservacionistas e conservacionistas, porém existem ainda muitas resistências - inclusive na comunidade acadêmica e na sociedade civil - quanto à possibilidade de haver modelos de unidades de conservação que integrem as populações tradicionais às áreas protegidas.

As Unidades de Conservação (UCs) no Brasil estão divididas em dois tipos: Unidades de Proteção Integral, ${ }^{1}$ que têm como objetivo básico a preservação da natureza, sendo admitido apenas o uso indireto dos recursos naturais; e Unidades de Uso Sustentável, ${ }^{2}$ que têm como objetivo básico compatibilizar a conservação da natureza com o uso sustentável de parte de seus recursos naturais.

Até julho de 2005, no Brasil, já havia 478 unidades de conservação federais e estaduais de proteção integral delimitadas. Tamanho número de áreas ambientais espalhadas pelo território nacional resultou, desde então, em desapropriações, deslocamento de comunidades para assentamentos, restrições rígidas do uso das reservas naturais, e, ainda, na visi- 
tação de turistas (Silva, 2005). Todas essas consequências influíram na cultura das comunidades que viviam dentro ou ao redor das UCs.

O Parque Estadual do Jalapão (PEJ) corresponde a uma Unidade de Conservação (UC) de Proteção Integral, ou seja, está entre as categorias que visam à preservação das áreas naturais sem a presença humana. Sua implantação, pelo governo do Tocantins, deu-se a partir do modelo conservacionista. Por meio de "estudos técnicos", o Estado impôs à população local, de forma unilateral, uma Unidade de Proteção Integral. Por definição, tal modelo não permite que nenhuma população habite o interior do parque, no entanto há ali uma comunidade de cerca de 170 habitantes que há mais de cem anos vem se reproduzindo humana e culturalmente a partir de um modo de vida tradicional: a comunidade Mumbuca.

Dado o conflito socioambiental estabelecido, este artigo pretende discutir o caso da comunidade Mumbuca, ainda residente no Parque Estadual do Jalapão, refletindo sobre os desafios enfrentados pelas sociedades tradicionais, com sua cultura e modos de vida, em relação às práticas de conservação ambiental. Será que é possível a comunidade Mumbuca viver dentro do Parque Estadual do Jalapão (PEJ), reproduzindo-se física e socioculturalmente enquanto comunidade tradicional? E a preservação do PEJ será afetada pela permanência dessa comunidade em seus limites?

\section{Materiais e métodos}

A pesquisa foi realizada a partir de uma perspectiva etnográfica, em que se optou por dois enfoques diferenciados enquanto estratégia de investigação:

Primeiro, um enfoque local - a pesquisa "de dentro" da comunidade Mumbuca - para saber como eles vivem, pensam, representam a natureza, como se relacionam com o meio, para que fosse possível reconhecer e entender seus símbolos e significados, e saber se eles podem viver afastados daquele meio ambiente.

Segundo, uma pesquisa com os "de fora": os interlocutores do projeto Unidade de Conservação Parque do Jalapão, os representantes do Instituto Natureza do Tocantins (Naturatins), do governo do Tocantins; os interlocutores das ONGs que trabalham e defendem os Parques, políticos etc. Ou seja, atores sociais que traduzem a visão que as instituições têm sobre como se deve preservar o meio ambiente, sobre o que fazer com as populações que vivem nas UCs. 


\section{Pesquisa etnográfica}

A inserção na comunidade teve como objetivo primordial "apreender” a visão de mundo do outro. Segundo DaMatta (1987), para a Antropologia Social todo dado disponível é válido para a reflexão, sejam dados históricos, econômicos, políticos. Nada, segundo o autor, pode ser excluído para que se entenda o processo de vida social, porém isso só será possível se for feito do ponto de vista do "nativo", dentro da lógica e dignidade da população estudada, e é função do antropólogo descobrir essas categorias sociais (DaMatta, 1987, p. 150).

É, portanto, para chegar a esta postura (ou para chegar próximo a ela) que o etnólogo empreende sua viagem e realiza sua pesquisa de campo. Pois é ali que ele pode vivenciar sem intermediários a diversidade humana na sua essência e nos seus dilemas, problemas e paradoxos. (DaMatta, 1987, p. 150)

Sendo assim, ir ao campo algumas vezes - nesse movimento de ir e depois de algum tempo voltar -, tornar-se alguém conhecido, passar alguns dias dentro da comunidade, estar entre eles, participar das rotinas, tarefas, festas, conversar, trocar experiências, sem um roteiro pré-determinado, permitiu que o pesquisador pudesse perceber alguns anseios, expectativas, gostos, desprazeres daquela população, e, sobretudo, permitiu que criasse com eles a empatia necessária para o desenrolar da pesquisa científica.

A primeira visita à comunidade Mumbuca foi em junho de 2005, depois em abril de 2006. Retornamos em setembro e em novembro de 2008. Após a conclusão da pesquisa visitamos mais duas vezes a comunidade, em setembro e em novembro de 2009, para levar um exemplar do trabalho, participar dos resultados e acompanhar a Festa da Colheita do Capim Dourado.

A história do lugar foi obtida através de documentos do Naturatins (2003), que levantou a historiografia da região por fontes documentais: registros de Mateiros e Ponte Alta do Tocantins; e por fontes orais: a história foi contada por uma equipe multidisciplinar responsável pelo Plano de Manejo do Parque Estadual do Jalapão.

Essa história contada pelo Naturatins no Plano de Manejo é confrontada com aquela contada pelos moradores de Mumbuca, dentro da perspectiva dos "de dentro". A história dos mumbuquenses é de origem 
mítica, o que reforça os valores da comunidade e o sentimento de pertencimento ao lugar, como será visto mais adiante nos resultados, enquanto a história de formação contada no Plano de Manejo se faz com o olhar dos “de fora”, focando os ciclos migratórios da região.

Outro ponto a ser ressaltado e justificado é o método que permite usar um estudo de caso para o entendimento de uma prática recorrente. Ele só é possível pela natureza do objeto estudado. Primeiro, porque os Parques de Conservação, sejam estaduais ou nacionais, seguem as mesmas orientações paradigmáticas. Portanto, quando se estuda o relacionamento de uma UC desse tipo com as comunidades tradicionais, pode-se chegar a algumas conclusões válidas para a maior parte delas: "Muitas práticas conservacionistas, como a implantação de parques nacionais e reservas naturais, são marcadas pelo autoritarismo de muitas instituições governamentais e de várias instituições não governamentais conservacionistas nacionais e internacionais" (Diegues, 2000, p. 16). Segundo, porque a dependência do meio ao redor é uma característica comum às comunidades tradicionais:

Comunidades tradicionais estão relacionadas com um tipo de organização econômica e social com pouca ou nenhuma acumulação de capital, não usando força de trabalho assalariado. Nela, produtores independentes estão envolvidos em atividades econômicas de pequena escala, como agricultura e pesca, coleta e artesanato. Economicamente, portanto, essas comunidades se baseiam no uso de recursos naturais renováveis. (Diegues, 2005, p. 88-89)

Sendo assim, as dificuldades apresentadas por uma comunidade tradicional, ao viver dentro de um parque de conservação, são semelhantes às dificuldades das demais populações que vivem em situações similares, ou seja, dentro de reservas de proteção ambiental integral, uma vez que estas dependem da relação com o meio.

Se o paradigma adotado nas reservas é predominantemente preservacionista - de preservar a natureza isolada do homem, pois este prejudica a natureza (Diegues, 2000) -, essas populações, a partir do momento em que se veem inseridas em um parque de conservação, passam a ter problemas com os dirigentes desses parques, com os governos locais e com outras instituições como ONGs, INCRA, em relação à sua forma de manejo com o meio, comprometendo assim sua reprodução econômica, 
social e cultural. A prática de queimadas é um exemplo recorrente desses conflitos.

Partindo desses pressupostos metodológicos, os instrumentos utilizados para o conhecimento da comunidade Mumbuca foram:

1. Aplicação de 40 questionários - de 136 perguntas - divididos em cinco aspectos: a) perfil dos moradores e famílias; b) aspectos sociais; c) aspectos econômicos; d) aspectos culturais e simbólicos; e) perspectivas futuras. A finalidade desse levantamento foi ter uma visão geral da comunidade. Tratando-se de 58 famílias que moram no local, a aplicação desse número de questionários foi satisfatória para tecer um panorama sobre os temas abordados.

2. Realização de visitas de campo para compartilhar momentos diferentes da vida cotidiana da população.

\section{Atores institucionais: "os de fora"}

A pesquisa com os "de fora" foi direcionada aos agentes institucionais que trabalham com outras populações, outras unidades de conservação, em diversas situações. Esses agentes podem "traduzir" uma "postura universal” dessas instituições frente às áreas de preservação que eram o nosso objeto de estudo.

Uma vez que muitas entidades governamentais e não governamentais conservacionistas empregam grande número de cientistas naturais (engenheiros florestais, botânicos, biólogos) em cargos de direção, a visão "naturalizadora" é predominante nesses órgãos. Esses profissionais, por outro lado, não têm treinamento adequado para solução de conflitos [...]. (Diegues, 2000, p. 17)

Como o autor salienta, as instituições governamentais e não governamentais tendem a ter uma visão "homogênea” em relação à preservação de áreas ambientais, uma visão conservadora em razão da própria configuração do seu quadro funcional, o que valida o método empregado na pesquisa: entrevistar os funcionários de alto escalão dessas entidades.

Para descobrir se é possível a convivência em harmonia e um consenso do que seja um manejo sustentável para a área em questão, o olhar das instituições foi usado de forma comparativa com o olhar dos mumbuquenses. O que pensam os planejadores, os tutores e os administrado- 
res das áreas onde vive a comunidade Mumbuca? E o que a comunidade pensa deles?

Foram realizadas também entrevistas semiabertas, com um roteiro predeterminado, com coordenadores e assessores que trabalham em ONGs da área ambiental, intelectuais envolvidos com o tema ecológico ou sustentabilidade humana e políticos que em algum momento já se depararam com essa questão na sua vida pública. Essas entrevistas buscaram o posicionamento institucional referente a vários temas, porém o foco do estudo estava nas seguintes questões: o apoio ao modelo de UC de Proteção Integral; a permanência das comunidades tradicionais dentro das UCs de Proteção Integral; e qual seria a melhor maneira de se proceder em relação a essas populações que já se encontram em parques protegidos.

\section{Resultados e discussões}

A comunidade Mumbuca está no Jalapão há pelo menos três gerações. As anciãs, líderes da comunidade, ali nasceram, e na época da pesquisa estavam com 80 e 84 anos. Seus pais também nasceram ali, e o avô veio jovem para aquela região para se casar com uma índia. Dessa forma, os mumbucas têm a posse/propriedade daquelas terras há mais de cem anos.

Por outro lado, o Parque Estadual do Jalapão (PEJ) foi implantado no mesmo local em 2001, como uma Unidade de Conservação de Proteção Integral, a partir de uma determinação política justificada pela "relevância" ecológica do lugar (Naturatins, 2003).

O objeto de nossa pesquisa, na essência, era o embate, o conflito entre a comunidade tradicional e o Parque do Jalapão, que, apesar de compartilharem o mesmo espaço físico, por serem comunidade e instituição formadas de matrizes culturais distintas, têm visões antagônicas sobre a apreensão do meio ambiente, sobre conservação e sustentabilidade. Sendo assim, para saber o que pode ser negociado entre o PEJ e os mumbuquenses, foi necessário conhecer esse povo tradicional.

O que vimos, no nosso caso, é o "jeito de ser" da comunidade em relação à natureza. Por meio da pesquisa concluiu-se que a população mumbuquense tem um modo de ser histórico, com vínculo com o território local necessário para a reprodução do seu modo de vida físico e cultural. Ou seja, ser um mumbuquense é pertencer àquele lugar, que não diferen- 
cia natureza de gente. Fora dali as pessoas não existiriam dentro daquela concepção de ser, seriam outra coisa, mas não aquela "gente".

Para compreender melhor a relação entre a comunidade e a natureza, primeiro era preciso saber se eles tinham um vínculo com "aquele" lugar, pois, caso contrário, poderiam viver, enquanto comunidade, em qualquer outro local fora do Parque e não haveria o dilema de estar em uma área de preservação integral; e saber também se esse vínculo estabelecia uma relação depreciativa com o meio ambiente causando prejuízos ao PEJ.

Apego afetivo ao lugar, o lugar construído, "desvendado" pela pesquisa etnográfica

Quando uma jovem foi questionada se gostava dali, sua fala refletiu bem o espírito da população local: "Passei uns dias fora daqui, eu lembrava cada árvore e meu coração doía de saudades.” Ela havia passado menos de uma semana em Palmas, capital do Tocantins, a $320 \mathrm{~km}$ do PEJ.

Outras falas: "Esse é o nosso lugar junto com o nosso povo. Aqui é bom, a terra é boa e nós gostamos. Aqui é muito bom para cuidar dos filhos, não tem violência e é tranquilo. Eu gosto mesmo é daqui, não quero ir para lugar nenhum. Eu não aceito ir para outro lugar. Eu prefiro morrer aqui e vou brigar com todos que precisar. Eu gosto dessa terra, aqui é meu lugar. Gosto do Mumbuca, é herança que Deus me deu.”

Todas parecem uma só voz, demonstram um sentimento de amor e pertencimento ao lugar como se aquele fosse o único lugar possível de se construir a vida; demonstram

[...] o sentimento de pertencimento e/ou identidade [...] em relação aos territórios em que vivem. Nas palavras desse autor, o território consiste no [...] chão da população, isto é sua identidade, o fato e o sentimento de pertencer àquilo que nos pertence. O território é a base do trabalho, da residência, das trocas materiais e espirituais e da vida, sobre os quais ele influi. (Santos, 2000, apud Oliveira Filho, 2002, p. 108-109)

Se para eles, mumbuquenses, o espaço é o que é, dos seus ancestrais, da família, do lazer, o local de trabalho, e, por isso, o único local possível de reproduzir a vida social, o espaço da cidade na sociedade capitalista é um espaço fetichizado, "dá ao envoltório artificial da Terra uma significação cada dia mais equívoca, fazendo da paisagem uma espécie de mentira funcional" (Santos, 2004, p. 38). 
Na sociedade moderna, ao se adquirir um imóvel, muitas vezes o que se compra não são paredes e teto, compra-se "uma linda paisagem da janela principal", "ótima localização", "um lugar perfeito para você criar seus filhos", "um edifício de classe". São ideias que não estão no espaço adquirido, são colocadas artificialmente ali, dando-lhe significados que não lhe pertencem, para valorizá-lo como mercadoria. Nesse processo de alienação do espaço social, o que menos importa é sua forma, sua estrutura, ou sua função. Esses são os componentes centrais no conceito de espaço (Lefèbvre, 1961, 1974, apud Santos, 2004), mas, cegos pela ideia de um conteúdo e de um valor que na realidade esses espaços não têm, os consumidores pouco veem a metragem dos apartamentos (cada vez menores), se servem a que se destinam, se as famílias cabem dentro, se podem pagar pelos imóveis, se ficam perto do trabalho ou da escolha dos seus filhos etc.

Essa desconexão entre o território (espaço real) e a idealização que se faz do espaço traz como consequência o constante descontentamento com o lugar efetivo, pois o que se deseja não é onde se vive, mas o local que está por vir, com uma vista melhor, ou melhor vizinhança e localização.

Por tudo isso é que, muitas vezes, olhamos as casas de adobe de Mumbuca e não entendemos como seu povo ama tanto aquele espaço, enquanto nós pouco gostamos das nossas ilusões rebocadas, envidraçadas e arejadas artificialmente, sempre buscando a próxima conquista. É a diferença entre o território construído e vivido das comunidades tradicionais e o território fetichizado, idealizado, das sociedades modernas.

Segundo, Santos (2002), "o território não é apenas os sistemas de coisas naturais e de coisas superpostas. O território tem de ser entendido como território usado. O território usado é o chão mais a identidade. A identidade é o sentimento de pertencer àquilo que nos pertence. $\mathrm{O}$ território é o fundamento do trabalho, o lugar da resistência, das trocas materiais e do exercício da vida. O território em si não é uma categoria de análise de disciplinas históricas, como a geografia. É o território usado que é uma categoria de análise (Santos, 2002, p. 10).

Sendo assim, o território dos mumbuquenses é "aquele" lugar, e, para eles, sair do PEJ desfiguraria sua identidade cultural, não seriam mais "essa comunidade tradicional". 
A relação da comunidade Mumbuca com o seu meio ambiente

Entre os mumbuquenses, $85 \%$ declararam fazer parte da família de formação. O reconhecimento de ser um mumbuquense como parte da comunidade é ser parente direto das anciãs e matriarcas. Elas, por sua vez, é que "detêm" muitos dos conhecimentos tradicionais passados desde o avô, fundador da comunidade, até às gerações mais novas, os bisnetos.

Em primeiro lugar, a história da fundação do vilarejo é uma história mítica formada por personagens reais e fictícios. Percebendo esse fato, vimos que era necessário recolher o maior número possível das versões do mito, pois o mito de um grupo é formado por todas as suas versões: "A repetição tem a função própria que é de tornar manifesta a estrutura do mito. [...] Todo mito possui, pois, uma estrutura folheada que transparece na superfície, se é lícito dizer, no e pelo processo da repetição” (Lévi-Strauss, 2003, p. 264).

Estudamos o mito de Mumbuca no seu conjunto de repetições, uma vez que, se contado por uma só pessoa, tem-se apenas uma versão, e é nas recorrências que aparecerão os elementos fixos significativos para aquele grupo. Destarte, podem-se entender os pares de oposições, que mostraram os temores, as sagas, as histórias de superação de desafios que permitiu que o grupo se formasse, ou superasse um problema, até chegar ao tempo presente (Lévi-Strauss, 1978).

Dentro desse exercício teórico de "desmontar" as várias versões do mito e procurar desvendar sua estrutura, o "Mito de Origem" de Mumbuca pode ser compreendido como a seguinte "história mítica": "Nossos ancestrais eram migrantes dos estados vizinhos, Piauí e Bahia. Valentes negros escravos, alguns de olhos azuis. Vieram para cá há mais de cem e há menos de duzentos anos. Eram muito valentes. Os que vieram eram homens e vieram fugidos da seca e da escravidão, da vida difícil. Vieram para ficar, formar família, casar, construir uma nova comunidade e nunca mais voltar. As terras que ocuparam estavam desocupadas e foram mais de quatro léguas de terra, muito mais, porque não é só essa onde está a comunidade, tem mais com gente por aí espalhada (em terra espalhada). Quando chegaram, casaram-se com as índias selvagens que viviam nas aldeias das matas daqui. Tiveram que conquistar terras e índias. Mas eles venceram, porque eram capazes e autossuficientes, nunca precisaram de 
ninguém de fora, faziam seus próprios utensílios, até seus pratos e panelas eles faziam de barro."

A importância de contar e recontar esse mito de geração a geração tem o sentido de afirmar o direito da comunidade à terra, sua autossuficiência, seu direito de estar ali, que foi conquistado com bravura por seus ancestrais. Esse modo de formação da comunidade de vir de longe, “domar" índios selvagens e fixar-se naquele lugar inóspito, onde não havia ninguém "civilizado", dá sentido à vida autossustentável, independente de qualquer cultura exterior. Eles e o cerrado, eles e os animais, eles e a mata, eles e o gado, eles e a lavoura. Ou seja, todos os elementos culturais de fixação da identidade com a propriedade estão no mito de origem da população de Mumbuca, como também os de sentimento de permanência e independência: "venceram, vieram para não voltar e faziam seus próprios utensílios" (fala de uma Anciã, 2008).

A atividade de subsistência de Mumbuca está baseada no tripé "lavoura, gado e capim-dourado", tanto na extração quanto no artesanato deste último. É uma economia de subsistência, em que a relação do homem com a natureza apresenta uma unicidade diferente do modo de produção capitalista.

Mesmo tendo uma diversidade de produtos que garantem o sustento de seus habitantes, a comunidade não produz excedente para acumulação, só o necessário para que as famílias reproduzam seu modo de vida a cada período. Dessa forma, é fundamental que eles tenham terra suficiente para o rodízio da roça, pasto nativo em abundância para criação do gado solto, acesso à colheita e manejo do capim dourado.

Apesar desse aparente "descompromisso" com o espaço e tempo e, consequentemente, do atrito com as regras de manejo do PEJ, os nativos têm um compromisso assumido há séculos com a natureza, onde são respeitados os tempos, os desgastes, os clamores do meio ambiente.

Na fala de um líder da comunidade do Prata - Jalapão (TO), vemos como a percepção do mundo "civilizado" dos manejos dos Parques é uma e a da população tradicional é outra: "Pois é, nóis não pode caçar... Pescar, nem sei. Se vê, aqui é tudo puro. O ar, a mata. Não tem poluição, mal tem estrada e já não tem peixe no rio. Eles não pode dizer que nóis acabamos com os peixes. Isso é lá das barragens que fazem de pôr o rio de um lado pro outro, e acaba tudo com os peixes. Isso eles não vê, nê?"

Esse debate é diuturno entre as comunidades tradicionais e os órgãos institucionais: qual a "forma certa de manejo a ser implantada"? São 
dois paradigmas civilizatórios distintos e incompatíveis. Incompatíveis muito mais devido ao preconceito do que a extensos trabalhos científicos de antropólogos, sociólogos, ou mesmo de cientistas naturais aparentemente bem intencionados.

De fato, o que se observa são as sociedades tradicionais protegendo suas áreas naturais, inclusive de invasões da nossa cultura civilizada (fazendas de soja ou de gado, produções madeireiras e outras atividades de alta lucratividade). No caso de Mumbuca, eles estão ali há bastante tempo, assim como outras comunidades tradicionais, e podemos atribuir em grande parte a preservação das belezas ecológicas do Jalapão a essas populações. Dessa forma, não há motivo algum para haver conflito entre os moradores daquela região, seus costumes, sua cultura centenária e as "normas e leis" do PEJ e do Estado brasileiro. Nem ao menos há uma necessidade de adaptação daquelas culturas à nossa cultura, pois isso seria um caos. Levaria à destruição da área num período muito curto, aumentando o excedente de produção, de acumulação e de consumo e, consequentemente, o lixo originado desse processo. Aumentaria também a necessidade de maior área para produzir e viver.

Por fim, respondendo à segunda pergunta proposta na análise de resultados: a comunidade Mumbuca não desenvolve atividades econômicas de alto impacto no Parque Estadual do Jalapão, sendo perfeitamente possível a convivência harmônica na região. O que se faz necessário é um conjunto de ações de gestão da Unidade de Conservação, com um diálogo entre os gestores do parque e os líderes comunitários, no sentido de estimular práticas ainda mais sustentáveis de produção e de vida. Destaca-se que algumas práticas dos mumbuquenses devem ser mais bem orientadas, como o manejo do solo, a extração do capim dourado e a preservação das matas quanto às queimadas.

Os resultados encontrados nesta pesquisa vão ao encontro das conclusões de Diegues (2000) sobre a implantação de Unidades de Preservação Integral. Não permitindo a presença do homem em seu interior sob nenhuma hipótese, mesmo com o argumento de defesa irrestrita do patrimônio natural, o poder público acaba adotando uma prática autoritária, pois, comumente, as populações, apesar de preexistirem nas áreas, são desconsideradas no momento de implantação da Unidade, como ocorreu no Parque Estadual do Jalapão.

Essas práticas conservacionistas muitas vezes desrespeitam os direitos civis das populações locais, promovendo o seu deslocamento 
forçado das áreas transformadas em parques. Para além disso, Diegues explica que, além de ignorarem os conhecimentos que as populações têm sobre o manejo de seus ambientes naturais, "muitos dos funcionários administradores de parques se comportam como verdadeiros 'senhores feudais', decidindo arbitrariamente a vida [...] de pessoas que viviam na floresta por várias gerações” (Diegues, 2000, p. 16).

\section{Considerações finais}

A comunidade Mumbuca não tem como viver fora da área em que vive há mais de uma centena de anos: ela não consegue viver em outro lugar, a não ser em "seu lugar". E, tampouco, ela consegue se reproduzir culturalmente dentro das especificações do PEJ e de suas normas de manejo, uma vez que estas não consideram a presença das populações humanas dentro da unidade. Entretanto, o modo de vida da comunidade é sustentável e, por isso, pode-se entender que não são essas populações que degradaram, degradam ou degradarão o meio, e, sim, o ambiente é degradado pelo modelo expansionista civilizatório predominante.

Mumbuca, assim como outras comunidades tradicionais espalhadas pelo país que insistiram em não desaparecer apesar da modernidade, depara-se hoje com o problema da "civilização" que se entrechoca e entra em conflito com ela. Seja pela "necessidade" de conservar o meio ambiente, seja pelo "imperativo" da barragem para a construção das usinas hidroelétricas, seja pela "obrigação" do Estado de apoiar projetos econômicos expansionistas, seja por qual motivo for, está se expulsando, cada vez mais, essa gente de suas terras.

Sabe-se, todavia, que fora dali eles não sobreviverão como cultura. Fora dali, eles serão números nas periferias das cidades. Os velhos morrerão e os adultos terão muita dificuldade de adaptação a qualquer atividade. Restarão os jovens: alguns destes talvez sejam salvos e lutarão para a retomada dos valores culturais de seus ancestrais. Por isso, não é a comunidade Mumbuca que deve "seguir a lei" e se retirar do seu local centenário, mas são as autoridades estaduais que devem ter o mínimo de sensatez e encontrar uma saída institucional e dialogada para o Parque Estadual do Jalapão.

É perfeitamente possível encontrar uma solução conciliatória para o dilema. Sem dúvida, algumas práticas produtivas da comunidade Mum- 
buca podem ser aperfeiçoadas, principalmente aquelas que trazem risco ao Parque como, por exemplo, as queimadas e o próprio manejo do capim dourado. Nesse sentido, pode ser necessário, por exemplo, estabelecer épocas para a colheita e o descanso, de forma a preservar ecologicamente a região. O poder público e a sociedade civil devem ser proativos no sentido de buscar essas alternativas, não exercendo, pura e simplesmente, o poder coercitivo, como várias vezes os atores estatais fazem, principalmente com os segmentos mais fragilizados da sociedade.

\section{Notas}

1. Estão subdivididas em cinco categorias: Estação Ecológica, Reserva Biológica, Parque Nacional, Monumento Natural e Refúgio da Vida Silvestre.

2. Enquadram-se nesta tipologia: Área de Proteção Ambiental, Área de Relevante Interesse Ecológico, Floresta Nacional, Reserva Extrativista, Reserva de Fauna, Reserva de Desenvolvimento Sustentável e Reserva Particular do Patrimônio Natural.

\section{Referências}

ARAUJO, M. A. R. Unidades de Conservação no Brasil: da República à gestão de classe mundial. Belo Horizonte: SEGRAC Editora, 2007.

AZEVEDO, J. R. da R. A conservação da paisagem como alternativa à criação de áreas protegidas. Um estudo de caso do vale do Rio Negro na região do Pantanal (MS). Dissertação (Mestrado) - Universidade de São Paulo, São Paulo, 2002.

BACHA, C. J. C. O uso de recursos florestais e as políticas econômicas brasileiras: uma visão histórica e parcial de um processo de desenvolvimento. Estudos Econômicos, São Paulo, v. 34, n. 2, p. 393-426, 2004. Disponível em: <ohttp:// $\mathrm{w} w \mathrm{w}$.scielo.br/scielo.php?pid $=$ S0101-41612004000200007\&script $=\mathrm{sci}$ arttext\&tlng=en> ISSN 0101-4161. Acesso em: 28 mar. 2010.

BRASIL. Lei $n^{o}$ 9.985, de 18 de julho de 2000. Institui o Sistema Nacional de Unidades de Conservação da Natureza e dá outras providências. Brasília, 2000.

COUTO FILHO, V. de A. (Org.). Agricultura familiar: um olhar da Bahia sobre o meio rural brasileiro. Brasília, MDA. Rio de Janeiro: Garamond, 2007.

DAMATTA, R. Individualidade e Liminaridade: considerações sobre os ritos de passagem ea modernidade.Mana, v. 6, n. 1, p. 7-29, 2000. Disponível em: http://www. scielo.br/scielo.php?script=sci_arttext\&pid=S0104-93132000000100001\&lng $=$ en $\& n r m=i s o \_$Acesso em: 26 mar. 2009.

. O que faz o Brasil, Brasil?. Rio de Janeiro: Rocco, 1986.

Rocco, 1987. 
DIEGUES, A. C. Etnoconservação. 2. ed. , São Paulo: Annablume, (NUPAUP USP) 2000.

. O mito moderno da natureza intocada. 5. ed. , São Paulo: Hucitec, (NUPAUP - USP) 2004. $\overline{2} \overline{0} \overline{5}$.

. NOGARA, P. J. O nosso lar virou parque. 3. ed. São Paulo: NUPAUP - USP,

ENGELS, F. Introdução à dialética da natureza (1875/1876). Lisboa: Edições “Avante"/ Moscovo: Progresso, 1982. Disponível em: http://www.vermelho.org.br/img/ obras/dialetica_da_natureza.asp. Acesso em: 24 mar. 2009.

LEFF, E. Epistemologia ambiental. 4. ed. São Paulo: Cortez, 2006.

LÉVI-STRAUSS, C. Mito e Significado. Lisboa, Portugal: Edições 70, 1978. (Coleção Perspectiva).

. Antropologia Estrutural. 6. ed. Rio de Janeiro: Tempo Brasileiro, 2003. (Biblioteca Tempo Universitário, 7).

. Antropologia Estrutural Dois. 4. ed. Rio de Janeiro: Tempo Brasileiro, 1993. (Biblioteca Tempo Universitário, 45).

. O pensamento selvagem. 3. ed. Campinas, São Paulo: Papirus, 2002.

NATURATINS - Instituto Natureza do Tocantins. Plano de Manejo do Parque Estadual do Jalapão. Palmas (TO), 2003.

OLIVEIRA, A. M. S. Relação homem/natureza no modo de produção capitalista. Scripta Nova: Revista Electrónica de Geografia y Ciencias Sociales, Universidad de Barcelona. ISSN: 1138-9788. Depósito Legal: B. 21.741-98, v. VI, n. 119 (18), 2002.

OLIVEIRA FILHO, W. A. A política articulada de desenvolvimento territorial rural implementada no Estado da Bahia: uma análise descritiva (107-121). Parte II. In: PÁDUA, J. A. Um sopro de destruição: pensamento político e crítica ambiental no Brasil escravista (1786-1888). Rio de Janeiro: Jorge Zahar Editor, 2002.

SANTOS, M. Território e dinheiro. In: SANTOS, Milton; SOUZA, Maria Adélia A. de (Orgs.). Território, territórios. Niterói (RJ): PPGEO-UFF, 2002. Santos).

. Pensando o espaço do homem. São Paulo: Edusp, 2004. (Coleção Milton . Da totalidade ao lugar (Coleção Milton Santos). São Paulo: Edusp, 2005.

SILVA, J. M. C.; RYLANDS, A. B.; FONSECA G. A. B. O destino das áreas de endemismo da Amazônia. Revista Megadiversidade, Belo Horizonte, v. 1, n. 1, jul. 2005. Disponível em: http://www.conservation.org.br/noticias/noticia.php?id=99. Acesso em: 28 mar. 2010. 
Waldecy Rodrigues - Graduado em Ciências Econômicas pela Pontifícia Universidade Católica de Goiás Mestre em Economia pela Universidade de Brasília - Doutor em Ciências Sociais/Estudos em Desenvolvimento Comparado e Pós-Doutor em Economia pela Universidade de Brasília - Professor Adjunto e Pró-Reitor de Pesquisa e Pós-Graduação da Universidade Federal do Tocantins.

Thelma Valentina Fredrych - Graduada em Ciências Sociais pela Universidade de São Paulo - Mestre em Ciências do Ambiente pela Fundação Universidade Federal do Tocantins - Professora do Instituto Federal de Educação, Ciência e Tecnologia do Tocantins.

Recebido para publicação em 27 de julho de 2013 Aceito para publicação em 12 de novembro de 2013 